\title{
Adherence to clinical trial registration in countries of Latin America and the Caribbean, 2015
}

\author{
Pilar García-Vello, ${ }^{1}$ Emma Smith, ${ }^{1}$ Vanessa Elias, ${ }^{1}$ Carlos Florez-Pinzon, ${ }^{2}$ and \\ Ludovic Reveiz ${ }^{1}$
}

Suggested citation García-Vello P, Smith E, Elias V, Florez Pinzon C, Reveiz L. Adherence to clinical trial registration in countries of Latin America and the Caribbean, 2015. Rev Panam Salud Publica. 2018;42:e44. https:// doi.org/10.26633/RPSP.2018.44

ABSTRACT

Objective. To determine the prevalence of clinical trial registration in the International Clinical Trial Registry Platform (ICTRP) for studies from Latin America and the Caribbean (LAC) and to identify the key characteristics that lead to prospective and retrospective registration.

Methods. Across-sectional study identified published, clinical trial studies through a search of PubMed, LILACS (Latin American and Caribbean Center on Health Sciences Information), and the Cochrane Central Register of Controlled Trials. Studies were included if published on 1 January - 31 December 2015, at least one author was affiliated with at least one LAC country, the clinical trial was conducted in at least one LAC site, and the full text of the article was available. A manual search of reference lists was also conducted. ICTRP registration information and key trial characteristics were compared.

Results. Of 1502 CT references that met inclusion criteria, 297 were randomly-selected, 90.9\% of which were published in English, 65\% from Brazil, and $76.8 \%$ had a LAC author as the first author. The proportion of CT registered in the ICTRP was $59.9 \%$, of which $51.7 \%$ were registered prospectively. Clinicaltrials.gov was most frequently used registry $(84.8 \%)$, followed by the Registro Brasileiro de Ensaios Clínicos and the Registro Público Cubano de Ensayos Clínicos. Key characteristics that favored registration were being in study phase 3 or 4 or being a multi-center study. Data was compared to a similar study from 2013 that reported a registration rate of only $19.8 \%$.

Conclusions. Registration adherence and prospective registration have increased in LAC in recent years, but the proportion of unregistered CT remains high. While there are still many challenges to overcome, the adherence strategies implemented in recent years have proven effective.

Keywords Clinical trial as topic; registries; LILACS; MEDLINE; Latin America; Caribbean region.
It has been 13 years since the International Council of Medical Journal Editors

\begin{tabular}{l}
\hline The Office of Knowledge Management, \\
Bioethics, and Research, Pan American Health \\
Organization/World Health Organization \\
(PAHO/WHO), Washington, DC, United States
\end{tabular}

(ICMJE) issued a statement requiring the prospective registration of clinical trials

of America. Send correspondence to Ludovic Reveiz, reveizl@paho.org

Grupo de Investigación en Salud, Universidad de

La Sabana, Chía, Cundinamarca, Colombia.
(CT) as a condition for publication in a biomedical journal (1). While CT registries have been in place for at least five decades, no public and comprehensive international registry platform was available before the ICMJE mandate $(2-4)$. 
In 2004, the Mexico Global Forum and Ministerial Summit on Health Research addressed the vital role of research in the improvement and sustainable development of population health, with a specific emphasis on how to translate knowledge into action to improve health. A global CT registry was deemed as a vital mechanism to enhance the capacity to generate and disseminate knowledge and create "a network of international clinical trials registers to ensure a single point of access and the unambiguous identification of trials" (5). In May 2006, the WHO International Clinical Trial Registry Platform (ICTRP) was developed following the Summit's discussions of clinical trials transparency in health research and narrowing the disparities in health systems performance between developing and developed countries (6).

At present, the ICTRP forms a network comprising 16 existing Primary Registries and the ClinicalTrials.gov database (National Library of Medicine, Bethesda, MD, United States), all of which meet the WHO Registry Criteria or that are working with ICTRP towards becoming a Primary Registry. The ICTRP also provides a unique Universal Trial Number (UTN) to facilitate the explicit identification of CT.

In the last 10 years, the number of registered clinical trials has been increasing worldwide. To date (January 2017), the ICTRP has more than 340000 clinical trials in over 175 countries. Registries in Latin America, including the Brazilian registry of clinical trials (ReBEC), the $\mathrm{Cu}$ ban registry of clinical trials (RPCEC), and the Peruvian registry of clinical trials (CENCEC) contribute data to the ICTRP (7).

The CT registration initiative is an attempt by the scientific community to improve transparency and public confidence in the conduct of research, to minimize publication and reporting bias, and to give visibility to the entire investigation process. Although publication bias and selective reporting remain widespread (8 -10), the ICTRP has enabled the more extensive identification of clinical research. Van Enst and colleagues (11) stated that searching for additional trials in prospective trial registers when conducting a Cochrane systematic review could reduce this problem. The Cochrane Collaboration Handbook now recommends searching the ICTRP to identify ongoing trials when conducting a systematic review (12). Additionally, Scherer and colleagues found that Randomized Clinical Trial design methods not reported in conference abstracts are frequently available in the ClinicalTrials.gov registry (13).

While adherence to trial registration has increased in recent years, it is still difficult to get an accurate measurement. Some studies have been monitoring the prevalence of trial registration among published studies (14).

The objective of this study was to determine the prevalence of clinical trial registration with the ICTRP and to identify the key characteristics that lead to prospective and retrospective registration in Latin America and the Caribbean.

\section{MATERIALS AND METHODS}

A cross-sectional study identified published, clinical trial studies from Latin America and the Caribbean through a search of PubMed (U.S. National Library of Medicine, Bethesda, Maryland, United States), LILACS (Latin American and Caribbean Center on Health Sciences Information, PAHO/ WHO, São Paulo, Brazil), and the CENTRAL (Cochrane Central Register of Controlled Trials, The Cochrane Collaboration, London, United Kingdom). Studies were included if published on 1 January - 31 December 2015, at least one author was affiliated with at least one LAC country, the clinical trial was conducted in at least one LAC site, and the full text of the article was available (see Supplementary Materials for more details). To find any additional studies, a manual search was performed on the reference lists of retrieved, relevant articles.

A sample of references was randomly selected using a random number sequence generator by nosetup.org, an open access website. The titles and abstracts of these articles were verified before inclusion. Duplicated articles and those that did not meet inclusion criteria were excluded from the analysis. Data were extracted from full-text manuscripts into the data template. Extracted data included: reference, first author's country affiliation, and if the article was registered in an international CT registry recognized by the ICTRP network. Each registered CT was searched via the ICTRP search portal (http:/ /apps.who.int/trialsearch/) to assess if the study was prospectively or retrospectively registered.

Trial registration terms were defined as follows:

- Trial start date: date of the first patient visit.

- Trial registration date: date on which the study information was submitted to the trial registry.

- Prospectively registered: the trial start date (actual/anticipated) is the same or after trial registration date.

- Retrospectively registered: the trial start date (actual/anticipated) is prior to the trial registration date.

Additional information was extracted, including language, contact email, duration of the study and follow up, purpose of intervention, use of alternative therapy, trial phase, randomization, disease / condition studied, neglected disease as a topic, target sample size, gender, presence of children, pregnant women or other vulnerable populations, blinding, recruitment status, countries of recruitment, whether it was multinational or multicenter, approval of the ethics committee, and agreement consent. The main funding source of CT was categorized as "public," "private," "self-funded," or "not reported." An Internet search of funding sources was conducted to avoid misclassification. Trials were categorized according to trial registration status (registered or unregistered) and relative date (prospectively or retrospectively registered).

All the statistical analysis was performed with a significance (alpha) level of 0.05. Chi-square statistics and 2-tailed Fisher exact tests were used to examine the significance of the association between categorical variables. Multivariate Logistic Regression Models was used to compute the $\beta$ coefficients for known factors for trial registration. To develop a good-fit model, all significant variables derived from univariate analysis were entered into the model. Variables significant at 5\% were included in the model using stepwise backward elimination, with trial registration as the dependent variable. The statistical analysis was done using the IBM SPSS ${ }^{\circledR}$ Statistics software, version 17 (SPSS Inc., an IBM company, Chicago, Illinois, United States). 


\section{RESULTS}

\section{Baseline characteristics of clinical trials}

The database search returned 1502 results, from which 410 references were randomly selected and screened against the inclusion criteria. Of these, 113 references were excluded, mostly because they were not CT or were not conducted in a LAC country. The resulting 297 articles were included in the analysis (see Supplementary Materials for more details). Most of these articles were full-text publications, but 11 protocols and 3 posters were also included. Approximately 303763 participants were recruited across all included trials. English was the dominant publication language of the included articles $(90.9 \%)$, followed by Spanish (5.4\%) and Portuguese (3.7\%).

The affiliations of the publications were diverse and 107 (36\%) had multinational authors' affiliations. Although study authors were affiliated with 16 LAC countries, approximately $90 \%$ of publications were from just five: Argentina, Brazil, Chile, Cuba, and Mexico (see Supplementary Materials for more details). Around $76.8 \%$ of articles had a first author with an LAC affiliation. When first authors were not affiliated with a LAC country $(23.2 \%)$, they tended to be from the United States (8.1\%), the United Kingdom (2.4\%), Australia (2\%), Canada (2\%), or other countries (5.4\%). Over one-third $(36.7 \%)$ of the clinical trials were multicenter and almost one-quarter $(23.9 \%)$ were multinational. Overall, $32.7 \%$ of CT had private sponsors, $34.7 \%$ were publicly sponsored, $2 \%$ were self-funded, and $30.6 \%$ did not report their funding source. Although the proportion of CT funded by the private sector was higher than that funded by the public sector in most countries, in Brazil nearly 58\% were funded by the public sector.

The majority $(71.7 \%)$ of CT were related to treatment, while $17.2 \%$ were related to prevention, $3.7 \%$ to disease diagnosis, and $7.4 \%$ to others. About $16.5 \%$ of CT were phase 1 or phase 2 trials, $27.3 \%$ were phase 3 or phase 4 trials, and the vast majority $(56.2 \%)$ did not specify a phase. In addition, the majority of CT were randomized $(85.2 \%)$ and blinded (52.5\%).

Information on the recruitment of vulnerable participants, such as children, pregnant women, or other vulnerable populations (i.e., indigenous) was actively searched. Of the total, 52 trials $(17.5 \%)$ recruited children or pregnant women, 38 recruited children, 13 recruited women, and 1 recruited both pregnant women and children. None of the trials declared enrollment of other vulnerable populations, and 6 did not provide enough information to determine whether vulnerable participants of any kind had been included. Only 9 trials (3\%) studied neglected diseases.

In addition, ethical characteristics of the CT were considered. In all, 223 $(75.1 \%)$ of the trials reported the approval of an ethics committee and 236
$(79.5 \%)$ reported the collection of an informed consent. Only 204 (68.7\%) included both ethical requirements.

Most of the articles (77.1\%) were CT having 1-year or less follow up; $11.8 \%$ had a follow up at 2 years or more. Table 1 shows information related to other characteristics of the included trials.

\section{Trial registration}

Table 2 shows characteristics of all 297 clinical trials considered for review, according to registration status (registered or not registered). Table 3 shows

TABLE 1. Descriptive characteristics of studies $(n=297)$ included in a review of adherence to clinical trial registration in countries of Latin America and the Caribbean, 2015

\begin{tabular}{|c|c|c|}
\hline \multirow{2}{*}{ Characteristic } & \multicolumn{2}{|c|}{ Studies $(n=297)^{\mathrm{a}}$} \\
\hline & $n$ & $\%$ \\
\hline \multicolumn{3}{|c|}{ Affiliation in a country with a primary registry in the WHO Registry Network } \\
\hline Yes $^{b}$ & 200 & 67.3 \\
\hline No & 97 & 32.7 \\
\hline \multicolumn{3}{|l|}{ Multinational } \\
\hline Yes & 71 & 23.9 \\
\hline No & 224 & 75.4 \\
\hline Unclear & 2 & 0.7 \\
\hline \multicolumn{3}{|l|}{ Multicenter } \\
\hline Yes & 109 & 36.7 \\
\hline No & 118 & 39.7 \\
\hline Unclear & 70 & 23.6 \\
\hline \multicolumn{3}{|l|}{ Phase of study } \\
\hline Early (Phase 1-2) & 49 & 16.5 \\
\hline Late (Phase 3-4) & 81 & 27.3 \\
\hline Unclear & 167 & 56.2 \\
\hline \multicolumn{3}{|l|}{ Randomization } \\
\hline Yes & 253 & 85.2 \\
\hline No & 36 & 12.1 \\
\hline Unclear & 8 & 2.7 \\
\hline \multicolumn{3}{|l|}{ Blinding } \\
\hline Yes & 156 & 52.5 \\
\hline No & 90 & 30.3 \\
\hline Unclear & 51 & 17.2 \\
\hline \multicolumn{3}{|c|}{ Clinical trials related to alternative therapies ${ }^{c}$} \\
\hline Yes & 45 & 15.2 \\
\hline No & 252 & 84.9 \\
\hline \multicolumn{3}{|c|}{ Recruitment of vulnerable participants (e.g., children, pregnant women, indigenous) } \\
\hline Yes $^{\mathrm{d}}$ & 52 & 17.5 \\
\hline No & 239 & 80.5 \\
\hline Not reported & 6 & 2.0 \\
\hline \multicolumn{3}{|c|}{$\begin{array}{l}\text { a Numbers may not sum to total due to missing data, and percentages may not sum to } 100 \% \text { due to rounding. } \\
\text { b Only Brazil and Cuba had primary registries in the WHO Registry Network in } 2015 \text {. } \\
\text { c Alternative therapies where classified using Merriam-Webster's Dictionary definition. } \\
\text { d Total trials recruiting any vulnerable population is } 52: 38 \text { trials recruited only children; } 13 \text { only pregnant women; and } 1 \text {, } \\
\text { both children and pregnant women. }\end{array}$} \\
\hline
\end{tabular}


TABLE 2. Characteristics of clinical trials included in a study of adherence to clinical trial registration in countries of Latin America and the Caribbean, according to registration status $(n=297),{ }^{a} 2015$

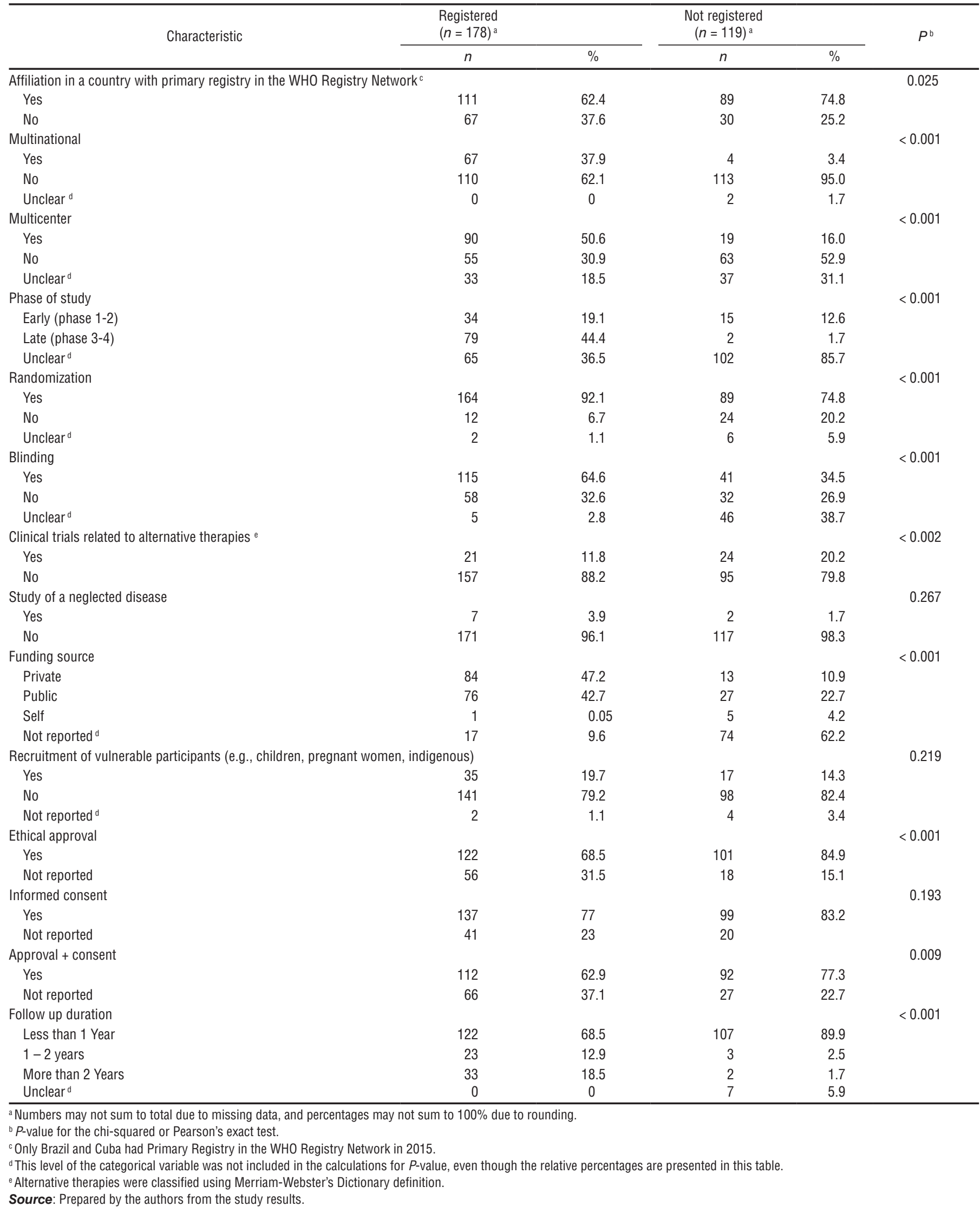


TABLE 3. Association between some characteristics of clinical trials and registration status (independent variable) using a multivariate model, $(n=297)$ in a study of adherence to clinical trial registration in countries of Latin America and the Caribbean, 2015

\begin{tabular}{|c|c|c|c|c|c|c|}
\hline \multicolumn{7}{|c|}{ Affiliation in a country with primary registry in the WHO Registry Network } \\
\hline Yes & 1.44 & $1.1-2.88$ & 0.006 & 1.99 & $1.02-2.87$ & 0.051 \\
\hline \multicolumn{7}{|l|}{ Phase of study } \\
\hline Late (phase $3-4$ ) & 7.81 & $3.76-16.23$ & $<0.001$ & 8.17 & $3.28-20.3$ & $<0.001$ \\
\hline \multicolumn{7}{|l|}{ Founding source } \\
\hline Public & & Reference & & & Reference & \\
\hline Private & 3.43 & $1.71-6.84$ & $<0.001$ & 1.46 & $0.65-3.27$ & 0.35 \\
\hline \multicolumn{7}{|l|}{ Multicentric } \\
\hline No & & Reference & & & Reference & \\
\hline Yes & 5.42 & $2.93-10.01$ & $<0.001$ & 3.83 & $1.63-8.99$ & 0.002 \\
\hline Not reported & 1.14 & $0.42-3.08$ & 0.78 & 2.41 & $0.67-8.68$ & 0.176 \\
\hline \multicolumn{7}{|l|}{ Language } \\
\hline English & & Reference & & & Reference & \\
\hline Spanish & 0.13 & $0.036-0.47$ & 0.002 & 0.27 & $0.045-1.66$ & 0.16 \\
\hline Portuguese & 0.21 & $0.055-0.82$ & 0.025 & 0.16 & $0.033-0.82$ & 0.029 \\
\hline
\end{tabular}

Source: Prepared by the authors from the study results.

characteristics of the 178 registered trials, according to their prospective or retrospective status. Both tables include categorical variables, including the phase of the study, randomization, binding, alternative therapy, funding source, ethical considerations, and follow-up duration. $P$-values associated with each categorical variable in Tables 2 and 3 are based on the chi-squared test for homogeneity with a significance (alpha) level of 0.05.

Of the 297 clinical trials included in the analysis, 178 (59.9\%) were registered, 92 of which $(51.7 \%)$ were retrospective. The majority of the registered trials $(84.3 \%)$ provided a registration number or link to the registration in the publication; the remainding $(15.7 \%)$ were found by manually searching the ICTRP.

The highest registration rates were found in Argentina, Brazil, Chile, Cuba, and Mexico. Of trials affiliated with countries that have a WHO-recognized registration platform, only $62.5 \%$ were registered; whereas, $37.6 \%$ of trials were registered for other countries. In other words, CT affiliated with both countries with a WHO-recognized national registration platform were more likely to be registered. There was also a significant difference in retrospective versus prospective registration rates according to the country affiliation.

It was found that $37.9 \%$ of registered CT were multinational, as compared with only $3.4 \%$ of unregistered CT $(P<0.001)$. There was also significant variation in multicenter studies based on registration status: $50.6 \%$ of registered CT were multicenter trials, as compared with only $16 \%$ of unregistered CT $(P<0.001)$.

The Clinicaltrials.gov registry was the most frequently used $(84.8 \%)$, followed by Brazil's ReBEC (9.6\%), other registries $(4.5 \%)$, and Cuba's RPCEC (1.1\%). Only $66.7 \%$ of the Cuban and $15.7 \%$ of the Brazilian CT used their own national registries (RPCEC and ReBEC, respectively). None of the registrations done outside of the Americas had a non-LAC first author.
All of the publications with a first nonLAC author were registered in Clinicaltrials.gov $(62 ; 89.9 \%)$, and the remaining (10.1\%) were not registered. Overall, most of the registration platforms, such as Clinicaltrials.gov and RPCEC, had retrospective registration rates from $48 \%-62 \%$, but ReBEC had a rate of $82.4 \%$.

Regarding funding, $47.2 \%$ of registered trials were privately funded versus only $10.9 \%$ of unregistered trials. Only $9.6 \%$ of registered trials did not report funding sources, as compared to $62.2 \%$ of unregistered trials $(P<0.001)$. Of multinational trials, $53.6 \%$ were privatelyfunded, $11.7 \%$ received exclusively public funds, none were self-funded, $23 \%$ had mixed funds, and $7.7 \%$ did not report their funding source $(P<0.001)$. Of CT assessing alternative therapies, only $6.2 \%$ were privately funded, $22.3 \%$ received public funding, 50\% were selffunded, $7.2 \%$ had mixed funds, and $14.3 \%$ did not report a funding source $(P<0.001)$. 
Registered trials showed greater variation in the follow-up time used to complete the CT as compared to unregistered trials (Table 2). There was no statistically significant difference between registered and unregistered trials nor between prospective and retrospective registered trials regarding the study purpose, the study of neglected diseases, and the recruitment of vulnerable study populations (Tables 2 and 3). Ethical considerations also did not show a statistically significant difference between prospectively and retrospectively registered trials (see the Supplementary Materials for more details).

\section{Multivariable analyses}

Table 3 shows the crude and adjusted (adj) odds ratios (OR), 95\% Confidence Intervals $(95 \% \mathrm{CI})$, and $P$-values for each independent variable. After adjustment, trial registration by phase was found to be significant $(P<0.001)$; trials in phases $3-4$ had 8.17 greater odds of being registered than those in phases $1-2$ (adj $95 \% \mathrm{CI}=3.28-20.32)$. A significant adjusted association was also seen with funding source; self-funded clinical trials had 0.05 the odds of being registered (adj $95 \% \mathrm{CI}=0.004-0.60 ; P=0.019)$ and clinical trials with unspecified funding sources had 0.078 the odds of being registered $(\operatorname{adj} 95 \% \mathrm{CI}=0.032-0.19 ; P<0.001)$, as compared to clinical trials with public funding. Clinical trials that were conducted in multiple study centers had greater odds of being registered than those conducted at a single center (adj $\mathrm{OR}=3.83$; adj 95\%CI = 1.63 - 8.99; $P=0.002$ ). Publication in Portuguese was also significant; clinical trials published in Portuguese had 0.16 the odds of being registered as compared to trials published in English (adj 95\%CI = 0.033 0.82; $P=0.029$ ).

\section{DISCUSSION}

Adherence to trial registration initiatives has improved in recent years. In 2013, the registration rate of randomized controlled trials was only $19.8 \%$ (13), but our study, which followed a similar methodology, found an overall registration rate of $59.9 \%$ in 2015. Moreover, among all registered trials, the rate of prospective registration increased from $6.9 \%$ to $48.3 \%$ in $2013-2015$ (14 - 16). This increase, over a relatively short time period, is a promising trend that may represent the increasing concern for the quality and transparency of clinical trials in LAC countries. In addition, the increase in registration adherence may have already positively impacted results reporting, as multiple recent studies have shown that new research is more likely to be reported $(17-19)$. All studies were conducted using a similar methodology, which provides a basis for a yearby-year comparison.

Previous studies have found that publication rates tend to be higher for CT registered after completion versus those registered prior to completion or with an unknown study status (20). A possible explanation may be that researchers are retrospectively registering their trials to comply with biomedical journal policies prior to submission for publication. In our study, only $31 \%$ of all studies were prospectively registered.

Brazil continues to dominate CT research in LAC. Its CT account for $65 \%$ of the total for the region in 2015, though its proportion has decreased slightly from the 70\% it held in 2013 (10). During that same period, CT publication by other LAC nations has increased-perhaps influencing the slight shift.

Although efforts have been made to improve the quality of $\mathrm{CT}$, another prevailing issue is the lack of adequate completeness of registration information $(21,22)$. Despite the relatively high rate of reporting on ethical considerations and informed consent (Table 2), reporting on important information was lacking. For example, funding source, inclusion criteria, and study phase were weakly detailed in many publications. Those incomplete publications tended to be the ones with lower registration rates (Table 2). The lack of information related to registration must be addressed as well. Medical journal publications should encourage the publication of the registration number, preferably in the methodology section of the abstract. The vast majority of the registered trials $(84.3 \%)$ provided a registration number or link to the registration in the publication; the remainder (15.7\%) was found by manually searching the ICTRP.

In general, registration adherence tended to be higher among specific groups. For example, trials in phases 3 and 4 represented $44.4 \%$ of the registered $\mathrm{CT}$, as compared to just $1.7 \%$ of the unregistered $(P<0.001)$. However, adherence was very low among other groups, such as CT about alternative therapies, which made up $11.8 \%$ of the registered CT, but $20.2 \%$ of the unregistered $(P<0.001)$.

The association between funding source and multinational status was analyzed. We found that $53.6 \%$ of the privately funded CT were multinational clinical trials as compared with only $11.7 \%$ that received public funding; $(P<0.001)$. We predict that the discrepancies in the association of funding status with multinational study status may be explained by the relatively greater availability of resources available to private sponsors (as compared to public, self, or unspecified funders) that enable privately funded studies to cooperate with international registrations and standards of clinical trials.

As shown in previous studies, privately funded CT are more frequently registered than are publicly funded trials $(23,24)$. Across all LAC countries, approximately $34 \%$ of CT are funded by the public sector. In Brazil, a leader in CT research, an even greater proportion of trials are funded by the public sector. Countries with a large proportion of publicly-funded studies also tend to be the countries with trial registries that form part of the ICTRP network. This may explain our observation that countries with registries within the Network have lower registration rates than those without one. That is, funding source (public versus private) is a confounding factor in the association between having a network-recognized registry and the rate of $\mathrm{CT}$ registration. In addition, our observation that publication in Portuguese is significantly associated with low registration rates may also be explained by this confounding phenomenon since Portuguese is the primary language of Brazil.

\section{Policy implications}

Several steps need to be taken to ensure prospective registration of clinical trials in Latin America and the Caribbean and worldwide (24). First, the importance of trial registration should be emphasized to all researchers, journal editors, reviewers, and national authorities. All need to further efforts to highlight the value of prospective trial registration, but especially those conducting trials under conditions (i.e., public funding) that have been associated with lower registration rates in the past. Public 
institutions, especially universities, should provide adequate training and support to researchers to encourage trial registration. In addition, there is a need to address the lack of registration and selective reporting among early phase clinical trials. Lastly, it is imperative that results reporting be addressed; information on methodology, ethical aspects, and source of funding was frequently inadequate.

\section{Limitations}

This study had some limitations. First, the database search was conducted on only three databases and limited to a 1-year period. It was also restricted to published trials; so, completed but unpublished trials would have been overlooked by the search strategy. As a result of these issues, findings may not be representative of all CT

1. DeAngelis C, Drazen JM, Frizelle FA, Haud C, Hoey J, Horton R, et al. Clinical trial registration: a statement from the International Committee of Medical Journal Editors. N Engl J Med. 2004;351:1250-1.

2. Dickersin K, Rennie D. Registering clinical trials. JAMA. 2003;290(4):516-23.

3. Simes RJ. Publication bias: the case for an international registry of trials. J Clin Oncol. 1986; 4:1529-1541.

4. International collaborative group on clinical trial registries. Position paper and consensus recommendations on clinical trial registries. Ad Hoc Working Party of the International Collaborative Group on Clinical Trials Registries. Clin Trials Metaanal. 1993;28(4-5):255-66.

5. Ministerial Summit on Health Research. The Mexico statement on health research. Mexico City; 2004. Available from: www. who.int/rpc/summit/agenda/en/mexico_statement_on\%20health_research2. pdf Accessed 29 January 2018.

6. Krleža-Jeriç K1, Lemmens T, Reveiz L, Cuervo LG, Bero LA. Prospective registration and results disclosure of clinical trials in the Americas: a roadmap toward transparency. Rev Panam Salud Publica. 2011;30(1): 87-96.

7. World Health Organization. International Clinical Trials Registry Platform. The WHO Registry Network, Primary Registries. Available from: www.who.int/ictrp/ network/primary/en/ Accessed 1 June 2016.

8. Fleming PS, Koletsi D, Dwan K, Pandis N. Outcome discrepancies and selective reporting: impacting the leading journals? PLoS One. 2015;10(5):e0127495. doi: 10.1371 /journal.pone.0127495

9. Raghav KP, Mahajan S, Yao JC, Hobbs BP, Berry DA, Pentz RD, et al. From protocols to publications: a study in selective reporting of outcomes in randomized trials in oncology.. J Clin Oncol. 2015;33(31):3583-90.
While there are still a lot of challenges
to overcome, the international registration

\section{REFERENCES}

published in LAC. Also, some CT may have been missed in the ICTRP when a trial did not have a registration number and did not use keywords. Furthermore, we only had access to what the original researchers published, which may not have been a complete picture of the actual trial or may not have accurately identified the registration as prospective or retrospective.

Due to missing or non-reported information, the quality of the analysis may have been affected. Some variables, such as study type, blinding, and multicenter status, which were missing in as many as $12 \%$ of the CT analyzed, may have been a potential source of bias.

\section{Conclusions}

10. Page MJ, McKenzie JE, Kirkham J, Dwan K, Kramer S, Green S, Forbes A. Bias due to selective inclusion and reporting of outcomes and analyses in systematic reviews of randomised trials of healthcare interventions. Cochrane Database Syst Rev. 2014;(10):MR000035.

11. van Enst WA, Scholten RJ, Hooft L. Identification of additional trials in prospective trial registers for Cochrane systematic reviews. PLoS One. 2012;7(8):e42812

12. Higgins JPT, Green S, eds. Cochrane Handbook for Systematic Reviews of Interventions, Version 5.1.0 (updated March 2011). London: The Cochrane Collaboration; 2011. Available from: http://handbook-5-1. cochrane.org/ Accessed 29 January 2018.

13. Scherer RW, Huynh L, Ervin AM, Taylor J, Dickersin K. ClinicalTrials.gov registration can supplement information in abstracts for systematic reviews: a comparison study. BMC Med Res Methodol. 2013;18(13):79.

14. Reveiz L, Villanueva E, Iko C, Simera I. Compliance with clinical trial registration and reporting guidelines by Latin American and Caribbean journals. Cad Saude Publica. 2013; 29(6):1095-100.

15. Hardt JL, Metzendorf MI, Meerpohl JJ. Surgical trials and trial registers: a crosssectional study of randomized controlled trials published in journals requiring trial registration in the author instructions. Trials. 2013;14:407. doi: 10.1186/1745-621514- 407

16. Rosenthal R, Dwan K. Comparison of randomized controlled trial registry entries and content of reports in surgery journals. Ann Surg. 2013;257(6):1007-15.

17. Alexander KP, Kong DF, Starr AZ, Kramer J, Chiswell K, Tasneem A, Califf RM. Portfolio of clinical research in adult cardiovascular disease as reflected in ClinicalTrials. gov. J Am Heart Assoc. 2013;2(5):e000009.

18. Viergever RF, Terry RF, Karam G. Use of data from registered clinical trials to identify adherence strategies implemented in recent years have proven to be effective. This study found that the proportion of CT registered in the ICTRP was $59.9 \%$, of which $51.7 \%$ were registered prospectively. Registration adherence and prospective registration have increased in Latin America and the Caribbean, but the proportion of unregistered trials remains high. More effort should be applied to promoting continued improvement in registration rates, regardless of the specific characteristics of the clinical trial.

\section{Conflicts of interest: None declared.}

Disclaimer. Authors hold sole responsibility for the views expressed in the manuscript, which may not necessarily reflect the opinion or policy of the RPSP/PAJPH and/or PAHO. gaps in health research and development. Bull World Health Organ. 2013;91(6):416-25.

19. Stockmann C, Sherwin CM, Koren G, Campbell SC, Constance JE, Linakis M, et al. Characteristics and publication patterns of obstetric studies registered in ClinicalTrials. gov. J Clin Pharmacol. 2014;54(4):432-7.

20. Riveros C, Dechartres A, Perrodeau E, Haneef R, Boutron I, Ravaud P. Timing and completeness of trial results posted at ClinicalTrials.gov and published in journals. PLoS Med. 2013;10(12):e1001566.

21. Viergever RF, Karam G, Reis A, Ghersi D. The quality of registration of clinical trials: still a problem. PLoS One. 2014;9(1):e84727.

22. Dickersin K, Rennie D. The evolution of trial registries and their use to assess the clinical trial enterprise. JAMA. 2012;307(17):1861-4.

23. Reveiz L, Sangalang S, Glujovsky D, Pinzon CE, Asenjo Lobos C, Cortes M, et al. Characteristics of randomized trials published in Latin America and the Caribbean according to funding source. PLoS ONE. 2013;8(2): e56410. doi: 10.1371/journal.pone.0056410

24. Bourgeois F, Murthy S, Mandl KD. Outcome reporting among drug trials registered in ClinicalTrials.gov. Ann Intern Med. 2010; 153(3):158-166. doi: 10.7326/0003-4819-1533-201008030-00006

25. Scott A, Rucklidge JJ, Mulder RT. Is mandatory prospective trial registration working to prevent publication of unregistered trials and selective outcome reporting? An observational study of five psychiatry journals that mandate prospective clinical trial registration. PLoS One. 2015;10(8):e0133718. doi: 10.1371/journal.pone.0133718

Manuscript received on 23 February 2017. Accepted for publication on 31 October 2017. 
RESUMEN Objetivo. Determinar la prevalencia del registro de ensayos clínicos de América Latina y el Caribe en la Plataforma de Registros Internacionales de Ensayos Clínicos (ICTRP, por su sigla en inglés) y definir los elementos clave que fomentan el registro prospectivo y retrospectivo de estudios.

\section{Cumplimiento del registro de ensayos clínicos en los países de América Latina y el Caribe, 2015}

Palabras clave
Métodos. Se realizó un estudio transversal para encontrar los ensayos clínicos publicados mediante una búsqueda en PubMed, LILACS (Centro Latinoamericano y del Caribe para Información en Ciencias de la Salud) y el Registro Central Cochrane de Ensayos Clínicos Controlados. Se incluyeron los estudios que habían sido publicados entre el 1 de enero y el 31 de diciembre del 2015, que tenían cuando menos un autor afiliado a uno o más países de América Latina y el Caribe, que se habían realizado al menos en un centro de América Latina y el Caribe, y que tenían el texto completo del artículo disponible. También se llevó a cabo una búsqueda manual en listas de referencia. Se comparó la información sobre registros de la ICTRP y las características clave de los ensayos clínicos.

Resultados. De las 1502 referencias que cumplieron los criterios de inclusión, se seleccionaron 297 aleatoriamente. De estas, 90,9\% se habían publicado en inglés, 65\% eran de Brasil y 76,8\% tenían como primer autor un investigador de América Latina y el Caribe. La proporción de ensayos clínicos registrados en la ICTRP fue de 59,9\%, de los cuales $51,7 \%$ se habían registrado prospectivamente. Clinicaltrials.gov fue el registro usado con mayor frecuencia $(84,8 \%)$, seguido por el Registro Brasileiro de Ensaios Clínicos y el Registro Público Cubano de Ensayos Clínicos. Se determinó que las características clave que favorecían el registro eran que fuese un estudio de fase 3 o 4 o un estudio multicéntrico. Se compararon los datos con un estudio similar del 2013 en el que se había informado que la tasa de registro era de apenas 19,8\%.

Conclusiones. En América Latina y el Caribe se ha observado en los últimos años un aumento en el cumplimiento del registro y del registro prospectivo de ensayos clínicos, pero la proporción de estudios sin registrar sigue siendo alta. Sin embargo, aunque persisten muchos retos que se deben superar, las estrategias adoptadas en los últimos años para que se cumpla este requisito han sido eficaces.

Ensayos clínicos como asunto; sistema de registros; LILACS; MEDLINE; América Latina; Región del Caribe.
RESUMO

Adesão ao registro de ensaios clínicos em países da América Latina e Caribe, 2015
Objetivo. Determinar a prevalência do registro de estudos clínicos na Plataforma Internacional de Registro de Ensaios Clínicos (ICTRP) para estudos realizados na América Latina e Caribe (ALC) e identificar as principais características que conduzem ao registro prospectivo e retrospectivo.

Métodos. Em um estudo transversal, foram identificados os estudos clínicos publicados através de uma busca nas bases de dados PubMed, LILACS (Centro LatinoAmericano e do Caribe de Informação em Ciências da Saúde) e Cochrane Central Register of Controlled Trials (CENTRAL). Foram incluídos estudos publicados de $1^{\circ}$. de janeiro a 31 de dezembro de 2015, em que pelo menos um dos autores provinha de um país da ALC, realizados em um ou mais centros na ALC e que apresentavam o texto completo disponível. Foi também feita uma busca manual das listas de referências. Foram comparados os dados sobre o registro na ICTRP e as principais características dos estudos.

Resultados. Das 1.502 referências de estudos clínicos que atenderam os critérios de inclusão, 297 foram selecionadas aleatoriamente. Verificou-se que 90,9\% dos estudos foram publicados em inglês, 65\% eram provenientes do Brasil e 76,8\% tinham como primeiro autor um pesquisador da ALC. O percentual de registro dos estudos clínicos na ICTRP foi de 59,9\%, sendo 51,7\% registrado de forma prospectiva. Clinicaltrials. gov foi o registro mais usado $(84,8 \%)$, seguido do Registro Brasileiro de Ensaios Clínicos e do Registro Público Cubano de Ensayos Clínicos. As principais características que contribuíram para o registro foram ser estudo de fase 3 ou 4 ou multicêntrico. Os dados foram comparados com um estudo semelhante realizado em 2013 que verificou uma taxa de registro de apenas $19,8 \%$. 
Conclusões. Houve um aumento na adesão ao registro e no registro prospectivo na ALC nos últimos anos, porém o percentual de estudos clínicos não registrados continua alto. Embora ainda existam muitos desafios a serem vencidos, as estratégias de adesão implementadas nos últimos anos têm sido eficazes.

Palavras-chave Ensaios clínicos como assunto; sistema de registros; LILACS; MEDLINE; Região do Caribe. 